\title{
Costa Rica sin Fronteras
}

Pensar en Movimiento:

Revista de Ciencias del Ejercicio y la Salud

ISSN 1659-4436

Vol. 14, No.2, pp. 1-3

\section{COSTA RICA SIN FRONTERAS \#14}

En esta sección se publican los resúmenes en español de artículos que han sido publicados por investigadoras/es de universidades costarricenses en otras revistas en el mundo, con su debida referencia al trabajo original, y con una breve explicación de dónde se realizó la investigación. Los artículos originales han sido publicados en otros idiomas; las revistas tienen consejo editorial y manejan un proceso de revisión por pares.

Los resúmenes corresponden a estudios relacionados con las ciencias del ejercicio y la salud, que se conforman a los criterios generales de la revista, esto es, se trata de "... estudios experimentales o que hagan recomendaciones concretas para solucionar problemas o preguntas relevantes (...) trabajos originales o de meta-análisis." Solicitamos a las personas que han publicado este tipo de trabajos en otros idiomas que no los hagan saber, para incluir sus resúmenes en futuras entregas de esta sección

Luis Fernando Aragón V., Ph.D., FACSM

Director, PENSAR EN MOVIMIENTO 


\section{LA UTILIZACIÓN DE BLOQUEADORES SOLARES Y LA PRODUCCIÓN DE SUDOR EN HOMBRES Y MUJERES}

Aburto-Corona, J. \& Aragón-Vargas, L. (2016). Sunscreen Use and Sweat Production in Men and Women. Journal of Athletic Training 51(9): 696-700. doi: http://dx.doi.org/10.4085/1062-6050-51.11.01 Recuperado de http://natajournals.org/doi/abs/10.4085/1062-6050-51.11.01

Contexto: Los protectores solares son importantes para proteger la piel durante el ejercicio al aire libre, pero podrían interferir con la sudoración.

Objetivo: Medir el efecto de dos protectores solares, resistentes al agua, sobre la sudoración localizada en hombres y mujeres que se ejercitan en el calor, y comparar dichos efectos con la inhibición esperada producto de utilizar un antitranspirante.

Diseño: Estudio cruzado aleatorizado.

Marco: Ejercicio en el calor (temperatura ambiental $=30.2^{\circ} \mathrm{C} \pm 0.4^{\circ} \mathrm{C}$ bulbo seco y $58 \% \pm 4.3 \%$ humedad relativa) en un laboratorio de ambiente controlado.

Pacientes u otros participantes: Veinte estudiantes universitarios activos, aparentemente saludables: 10 hombres (edad $=22.5 \pm 2.8$ años, estatura $=1.771 \pm 0.069 \mathrm{~m}$, masa corporal $=70.2 \pm 11.0 \mathrm{~kg}$ ) y 10 mujeres (edad $=22.2 \pm 3.2$ años, estatura $=1.625 \pm 0.075 \mathrm{~m}$, masa corporal $=57.7 \pm 7.9 \mathrm{~kg}$ ).

Intervención: Los participantes ejecutaron dos sesiones de ejercicio, en días consecutivos, con parches para recolectar sudor adheridos a la región escapular derecha e izquierda. Se le asignaron los tratamientos cutáneos (antitranspirante; filtro solar orgánico químico, protector solar A; bloqueador solar físico inorgánico, protector solar $\mathrm{B}$; sin loción) aleatoriamente a cada lado y cada sesión. Los participantes pedalearon a $79 \% \pm 1 \%$ de la frecuencia cardíaca máxima durante 20 minutos en el calor. Medida del resultado principal: Tasa de sudoración localizada escapular.

Resultados: Ninguna de las medidas de la línea de base, ni de las condiciones ambientales, ni de las sesiones de ejercicio, mostró diferencias entre los tratamientos cutáneos. La tasa de sudoración localizada escapular fue menor para el tratamiento con antitranspirante $\left(88.3 \mu \mathrm{L} / \mathrm{min}^{\prime} \cdot \mathrm{dm}^{2}\right.$; intervalo de confianza $[\mathrm{IC}]$ de $95 \%=82.0,94.7 \mu \mathrm{L} / \mathrm{min} \cdot \mathrm{dm}^{2}$ ) y con el bloqueador solar físico inorgánico (protector solar B) $\left(99.3 \mu \mathrm{L} / \mathrm{min} \cdot \mathrm{dm}^{2} ; \mathrm{Cl} 95 \%=93.1,105.5 \mu \mathrm{L} / \mathrm{min} \cdot \mathrm{dm}^{2}\right)$, que para el tratamiento con filtro solar orgánico químico (protector solar A) $\left(114.8 \mu \mathrm{L} / \mathrm{min} \cdot \mathrm{dm}^{2}\right.$; Cl $\left.95 \%=108.8,120.6 \mu \mathrm{L} / \mathrm{min} \cdot \mathrm{dm}^{2}\right)$ o sin loción $\left(122.6 \mu \mathrm{L} / \mathrm{min} \cdot \mathrm{dm}^{2} ; \mathrm{Cl} 95 \%=116.2,129.0 \mu \mathrm{L} / \mathrm{min} \cdot \mathrm{dm}^{2} ; P<.01\right)$.

Conclusiones: El bloqueador solar físico inorgánico, protector solar $\mathrm{B}$, restringió la sudoración efectiva tanto como el antitranspirante; mientras tanto, el tratamiento con filtro solar orgánico químico, protector solar A, no fue distinto del tratamiento control. A estas alturas, no es posible identificar el ingrediente específico responsable de este efecto. 
Este estudio se realizó en el Centro de Investigación en Ciencias del Movimiento Humano de la Universidad de Costa Rica (CIMOHU). Colaborador: Luis Fernando Aragón-Vargas.

La revista Journal of Athletic Training tiene un factor de impacto de 2.224 (Ver http://www.bioxbio.com/if/html/J-ATHL-TRAINING.html). 